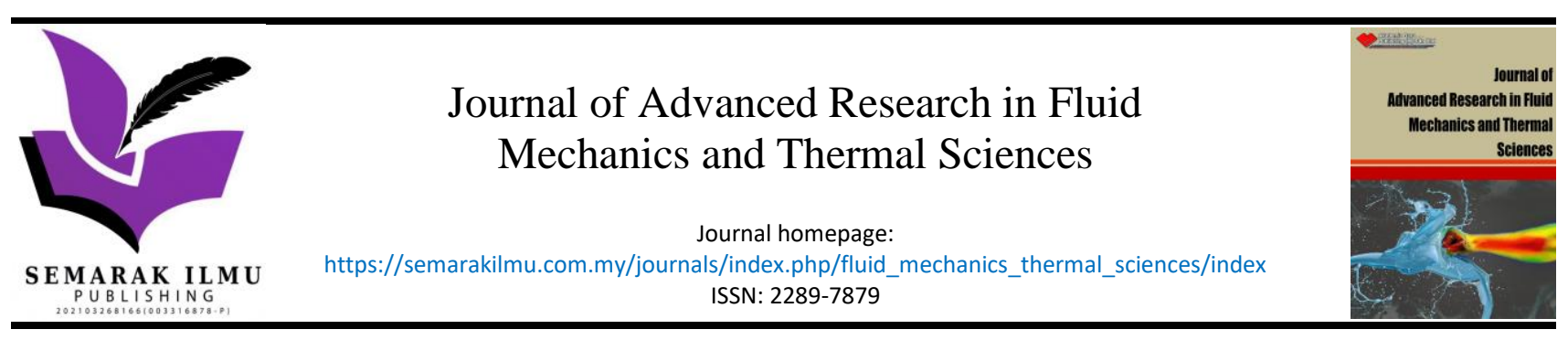

\title{
Radiative Mixed Convection Flow Over a Moving Needle Saturated with Non-Isothermal Hybrid Nanofluid
}

\author{
Sultana Jahan ${ }^{1}$, M. Ferdows ${ }^{1,}{ }^{*}$, Md. Shamshuddin², Khairy Zaimi ${ }^{3}$ \\ Research Group of Fluid Flow Modelling and Simulation, Department of Applied Mathematics, University of Dhaka, Dhaka-1000, Bangladesh \\ Department of Mathematics, Vaagdevi College of Engineering (Autonomous), Warangal, Telangana, India \\ Institute of Engineering Mathematics, Universiti Malaysia Perlis, Pauh Putra Campus, 02600 Arau, Perlis, Malaysia
}

\section{ARTICLE INFO}

\section{Article history:}

Received 9 May 2021

Received in revised form 25 August 2021

Accepted 27 August 2021

Available online 18 October 2021

\section{Keywords:}

Boundary layer flow; Mixed convection; Solar radiation; NonIsothermal; Viscous dissipation; Moving thin Needle; Hybrid nanofluid

\section{ABSTRACT}

\begin{abstract}
A steady incompressible boundary layer flow and heat transfer past on a moving thin needle saturated with hybrid nanofluid are investigated with the effects of solar radiation and viscous dissipation. The simulation is also influenced by the effects of thermophoresis and Brownian motion. We consider $\left(\mathrm{Al}_{2} \mathrm{O}_{3}-\mathrm{Cu}\right.$-water) as a hybrid nanofluid, where water is the base fluid and alumina and copper are the hybrid nanoparticles. By utilizing the technique of similarity transformations, we transformed the dimensional partial differential equations into dimensionless ordinary differential equations. Using the MAPLE software scheme, the transformed equations have been solved numerically. The graphical representation of different parameters including Mixed convection, Power-law exponent, Buoyancy ratio parameter, Eckert number are illustrated on velocity, temperature, the concentration of nanoparticles profiles and explained in detail. Skin friction coefficient, heat transfer rate, and mass transfer rate are also obtained numerically. With the presence of hybrid nanoparticles, the heat transfer rate is higher in all cases. In the temperature profile, we observed a reduction with the increasing values of the mixed convection parameter. It also revealed that greater values of volume fraction of nanoparticle $(\mathrm{Cu})$ reduce the mass transfer rate but accelerates the heat transfer rate.
\end{abstract}

\section{Introduction}

Boundary layer flow and heat transfer are the fundamental areas of modern fluid dynamics, which have a huge application in engineering and industrial fields [1]. The boundary layer is the region, where viscosity is dominant and the majority of the drag experienced by the body immersed in a fluid is created, the viscosity can be neglected on the outside of the boundary layer without any significant effects. It has several applications including polymer extrusions, wire drawing, nuclear reactor, etc. are examples of such flow in engineering and industrial processes.

The analysis of heat transfer and boundary layer flow has gathered immerse attention from researchers which focused on hybrid nanofluid, in the recent period. Hybrid nanofluid has more

\footnotetext{
* Corresponding author.

E-mail address: ferdows@du.ac.bd

https://doi.org/10.37934/arfmts.88.1.8193
} 
thermophysical properties and it has the capacity of raising the heat transfer rate because of the synergistic effects [2,3]. A better understanding of the thermal capacity of hybrid nanofluid in comparison with nanofluid has been analysed [4]. Hybrid nanofluid is considered as an effective heat transfer fluid rather than nanofluid and base fluid which uses for engineering application, to augment the heat transfer in the system [5]. It also has phenomenal application in the branches of the heat exchanger, nuclear system cooling, coolant in machining, transformer cooling, solar collector, micropower generation, heat sink, boiling, electronic cooling, refrigeration, drug reduction, biomedical [6]. With transpiration effect dual solution is noticed for both shrinking and stretching sheet, using buoyancy effect bifurcation is found which lead the solution towards a lower point $[7,8]$. Though the dual solution has been found for several values of radiation and suction parameter, the skin fraction factor decreased for the first solution [9]. The dual solution is also noticeable for the unsteadiness parameter or the elevated value of volume fraction of nanoparticle, critical value decreased in biaxial sheet $[10,11]$. With the wide range of Reynolds numbers, it is noticed that the heat transfer rate and skin friction coefficient got higher in the stretching/shrinking cylinder [12]. Also, to find out the effects of pressure drop disadvantage some experiments have been placed and implied positive results for hybrid nanofluid [13]. With the increasing values of volume fraction, it has noticed that the Nusselt number and the rate of heat transfer shows lessened effect throughout [14].

Over the last decades, the problem of boundary layer flow past thin needle has been proved as beneficial in terms of applications especially in industrial areas, for example, electronic devices, the hot wire anemometer, geothermal power generation [15]. It has also some vital aspects in the industries of engineering and medicine such as lubrication, blood flow problems, manufacturing dynamics of smart coating, wind prediction, transportation, and so on [16]. Forced convection boundary layer flow through a horizontal thin needle has been initiated which shown that the fluid and heat transfer were affected by solid volume fraction [17]. For further assumption, another problem was examined on the velocity and temperature profiles with a visible impact of needle size as well as solid volume fraction [18]. The laminar mixed convective flow of hybrid nanofluid is investigated for experimental learning $[19,20]$. A vertical thin needle with mixed convection boundary layer flow was obtained to find out the effect of solid volume fraction and boundary layer separation [21]. Also, an investigation has been done for nanomaterial over moving needle which find out, in the magnetic function the velocity profile demoted but the temperature profile elevated [22]. Apart from that, the dual solution has been found for another nanomaterial considering thermal radiation and discovered the velocity for both upper and lower solution depends on the size and movement of the thin needle [23].

This foregoing study is focused on the problem of an incompressible hybrid nanofluid in the boundary layer with the influence of exponential solar radiation and Viscous dissipation of steady mixed convective heat transfer flow past a non-isothermal moving thin needle [24-26]. Here we consider $\left(\mathrm{Al}_{2} \mathrm{O}_{3}-\mathrm{Cu}-\mathrm{Water}\right)$ as a hybrid nanofluid and the effects of Brownian motion and thermophoresis are included in this paper for this fluid. As the radiation and dissipation are invoked in this present study with other effects, the constructed new model has a great influence on the study of flow and heat transfer of hybrid nanofluid [27]. So, this particular topic of the thin needle could be exploded into real-life problems as well as industrial areas. For accuracy, the resulting data has been compared with the previously published data. To our best knowledge, no other investigation has been noted for this type of study and the resulting data are unique. 


\section{Physical Model and Formulation}

Study of a solar radiative dissipative, inspired by simulating the functional mixed convective hybrid nano-polymer coating boundary layer flow on a moving thin needle containing different nanoparticles. Temperature variation as $T=T_{w}=T_{\infty}+A x^{P}$ considered for the condition of the nonisothermal case, with surface temperature $T_{w}$ and the ambient temperature $T_{\infty}\left(T_{w}>T_{\infty}\right)$. The adopted cylindrical coordinate system $(x, r)$ (Figure 1 ) with axial and radial coordinates, respectively. Here the needle moves with a constant speed in a moving fluid with the same speed, $U_{\infty}$ is the nanoparticle concentration at the surface, $C_{w}$ and $C_{\infty}$ is the ambient nanoparticle concentration. The properties of nanofluid are assumed to be constant. The corresponding governing equations, under the above assumptions describing the 2D Hybrid nanofluid boundary layer flow, are obtained by amalgamating earlier models $[24,26,27]$.

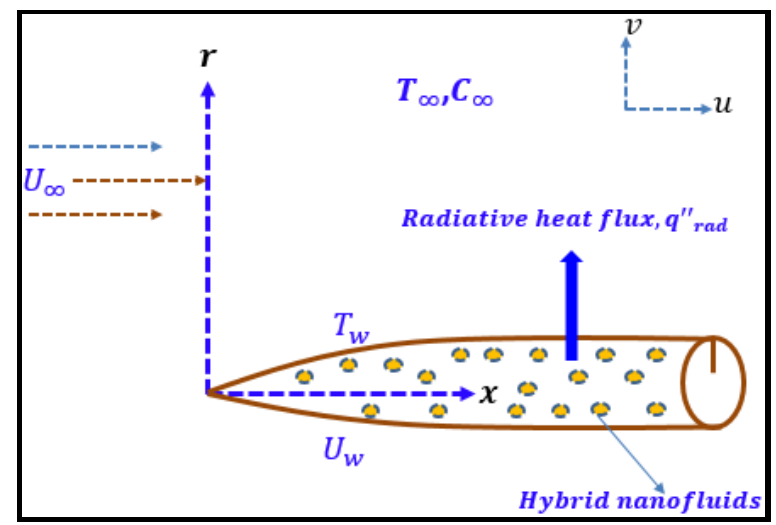

Fig. 1. Flow geometry of hybrid nanofluid through thin needle

$\frac{\partial}{\partial x}(r u)+\frac{\partial}{\partial r}(r v)=0$

$\mathrm{u} \frac{\partial u}{\partial x}+v \frac{\partial u}{\partial r}=\frac{\mu_{h n f}}{\rho_{h n f}} \frac{1}{r} \frac{\partial}{\partial r}\left(r \frac{\partial u}{\partial r}\right)+\frac{1}{\rho_{f}}\left[\left(1-C_{\infty}\right) \rho_{f \infty} \beta\left(\mathrm{T}-T_{\infty}\right)-\left(\rho_{p}-\rho_{f \infty}\right)\left(\mathrm{C}-C_{\infty}\right)\right] \mathrm{g}$

$\mathrm{u} \frac{\partial T}{\partial x}+v \frac{\partial T}{\partial r}=\frac{1}{r} \frac{\kappa_{h n f}}{\left(\rho C_{p)_{h n f}}\right.} \frac{\partial}{\partial r}\left(r \frac{\partial T}{\partial r}\right)+\sigma\left[D_{B} \frac{\partial C}{\partial r} \frac{\partial T}{\partial r}+\frac{D_{T}}{T_{\infty}}\left(\frac{\partial T}{\partial r}\right)^{2}\right]+\frac{1}{\left(\rho C_{p)_{h n f}}\right.} \frac{\partial q_{r a d}^{\prime \prime}}{\partial r}+\frac{\mu_{h n f}}{\left(C_{p)_{h n f}}\right.}\left(\frac{\partial u}{\partial r}\right)^{2}$

$u \frac{\partial C}{\partial x}+v \frac{\partial C}{\partial r}=\frac{D_{B}}{r} \frac{\partial}{\partial r}\left(r \frac{\partial C}{\partial r}\right)+\frac{D_{T}}{T_{\infty}} \frac{1}{r} \frac{\partial}{\partial r}\left(r \frac{\partial T}{\partial r}\right)$

Boundary conditions for the flow geometry are

$\mathrm{u}=U_{\infty} \varepsilon, \quad v=v_{w}, \mathrm{~T}=T_{w}=T_{\infty}+A x^{P}, D_{B} \frac{\partial C}{\partial r}+\frac{D_{T}}{T_{\infty}} \frac{\partial T}{\partial r}=0$ at $\mathrm{r}=\mathrm{R}(\mathrm{x})$

$\mathrm{u} \rightarrow U_{\infty}, \mathrm{T} \rightarrow T_{\infty}, \mathrm{C} \rightarrow C_{\infty}$ as $\mathrm{r} \rightarrow \infty$

where, $A, p$ are constant, $\varepsilon$ is constant moving parameter, $u$ and $v$ are the velocity components in $(x, r)$ directions, the surface of the thin needle is described by $\mathrm{R}(\mathrm{x}), D_{T}$ and $D_{B}$ are thermophoretic diffusion and Brownian diffusion coefficients, respectively, the effective heat capacity ratio, hybrid nanofluid's temperature, nanoparticle concentration and mass flux velocity are represented with $\sigma, T$, 
$\mathrm{C}$ and $v_{w}$ respectively, heat capacity, thermal conductivity, dynamic viscosity and density of hybrid nanofluid flow are characterized by $\left(\rho C_{p}\right)_{h n f}, k_{h n f}, \mu_{h n f}$ and $\rho_{h n f}$ respectively. Further, the nanoparticle volume fractions of $\mathrm{Al}_{2} \mathrm{O}_{3}$ and $\mathrm{Cu}$ are symbolized by $\varphi_{1}$ and $\varphi_{2}$ while their solid components are indicated by the subscripts $\mathrm{n} 1$ and $\mathrm{n} 2$, respectively. Thermophysical properties are listed in Table 1.

\section{Table 1}

Thermophysical properties of nanoparticles and water [14,23]

\begin{tabular}{llll}
\hline Thermophysical properties & Water & $\mathrm{Cu}$ & $\mathrm{Al}_{2} \mathrm{O}_{3}$ \\
\hline$\rho\left(\mathrm{kg} / \mathrm{m}^{3}\right)$ & 997.1 & 8933 & 3970 \\
$C_{p}(\mathrm{~J} / \mathrm{kgK})$ & 4179 & 385 & 765 \\
$k(\mathrm{~W} / \mathrm{mK})$ & 0.613 & 400 & 40 \\
\hline
\end{tabular}

Eq. (1)-(5) are formidable to solve even with numerical methods. It is pertinent therefore to simplify them with the help of similarity transformations and dimensionless quantities assuming from $[24,27]$

$\psi=v_{f} \times f(\eta), \theta(\eta)=\frac{\mathrm{T}-T_{\infty}}{T_{w}-T_{\infty}}, \varphi(\eta)=\frac{\mathrm{C}-C_{\infty}}{C_{\infty}}, \eta=\frac{U_{\infty} r^{2}}{v_{f} x}, q_{r a d}^{\prime \prime}=1-\exp \left(-a_{1} r\right), \mathrm{R}(\mathrm{x})=\left(\frac{v_{f} c x}{U_{\infty}}\right)^{\frac{1}{2}}$

Using Eq. (6), Eq. (2) to Eq. (5) become

$2 \frac{c 1}{c 2}\left(\eta f^{\prime \prime}\right)^{\prime}+f f^{\prime \prime}+\frac{\xi \theta}{4}-\frac{N r \phi}{4}=0$

$\frac{1}{\operatorname{Pr}} \frac{c 4}{c 3}\left(\eta \theta^{\prime}\right)^{\prime}+\frac{1}{2} f \theta^{\prime}-\frac{1}{2} P f^{\prime} \theta+\eta\left[N b \phi^{\prime} \theta^{\prime}+N t \theta^{\prime 2}\right]+\frac{c 1}{c 3} 4 E c \eta f^{\prime \prime 2}+\frac{G a}{2} c 5 \exp \left(-a \eta^{\frac{1}{2}} R e^{\frac{-1}{2}}\right)=0$

$2\left(n \varphi^{\prime}\right)^{\prime}+S c f \phi^{\prime}+2 \frac{N t}{N b}\left(n \theta^{\prime}\right)^{\prime}=0$

Subject to

$\mathrm{f}(\mathrm{c})=\varepsilon \mathrm{c}, f^{\prime}(\mathrm{c})=\frac{\varepsilon}{2}, \theta(c)=1, N b \phi^{\prime}(c)+N t \theta^{\prime}(c)=0$

$f^{\prime}(\eta) \rightarrow \frac{1}{2}, \theta(\eta) \rightarrow 0, \phi(\eta) \rightarrow 0$ as $\eta \rightarrow \infty$

where, $E c, \xi, G r_{x}, R e, \varepsilon, N r, P r, S c, N t, N b$ signifies respectively Eckert number, local Grashof number, Reynolds number, constant moving parameter, buoyancy ratio parameter, PrandtI number, Schmidt number, thermophoresis and Brownian motion parameters, respectively. The needle moves away from the origin if $\varepsilon>0$ and moves toward the origin if $\varepsilon<0$. The dimensionless flow parameters arising in Eq. (7)-(10) have the following mathematical definitions

$$
\begin{aligned}
& \operatorname{Pr}=\frac{v_{f}\left(\rho c_{p}\right)_{f}}{k_{f}}, \mathrm{Sc}=\frac{v_{f}}{D_{B}}, N t=\frac{\sigma D_{T}\left(T_{w}-T_{\infty}\right)}{v_{f} T_{\infty}}, E c=\frac{U_{\infty}^{2}}{c_{p}\left(T_{w}-T_{\infty}\right)^{\prime}}, \xi=\frac{G r_{x}}{R e^{2}}=\frac{\left(1-C_{\infty}\right)\left(T-T_{\infty}\right) g \rho_{f} \beta x}{U_{\infty}^{2} \rho_{f}}, \\
& \mathrm{Nr}=\frac{\left(C-C_{\infty}\right)\left(\rho_{p}-\rho_{f \infty}\right) g x}{U_{\infty}^{2} \rho_{f}}, N b=\frac{\sigma D_{B} C_{\infty}}{v_{f}}, \mathrm{Ga}=\frac{a x q_{r a d}^{\prime \prime}}{\left(T-T_{\infty}\right) 2 U_{\infty}}, \mathrm{c} 1=\frac{\mu_{n n f}}{\mu_{f}}=\frac{1}{\left(1-\varphi_{1}\right)^{2.5}\left(1-\varphi_{2}\right)^{2.5}} \\
& \mathrm{c} 2=\frac{\rho_{h n f}}{\rho_{f}}=\frac{\left(1-\varphi_{2}\right)\left[\left(1-\varphi_{1}\right) \rho_{f}+\varphi_{1} \rho_{n 1}\right]+\varphi_{2} \rho_{n 2}}{\rho_{f}}, \mathrm{c} 3=\frac{\left(\rho C_{p}\right)_{h n f}}{\left(\rho C_{p}\right)_{f}}=\frac{\left(1-\varphi_{2}\right)\left[\left(1-\varphi_{1}\right)\left(\rho C_{p}\right)_{f}+\varphi_{1}\left(\rho C_{p}\right)_{n 1}\right]+\varphi_{2}\left(\rho C_{p}\right)_{n 2}}{\left(\rho C_{p}\right)_{f}} \\
& \mathrm{c} 4=\frac{k_{h n f}}{k_{n f}}, \frac{k_{h n f}}{k_{f}}=\frac{k_{n 2}+2 \varphi_{2} k_{n 2}+k_{n f}\left(2-2 \varphi_{2}\right)}{k_{n 2}-\varphi_{2} k_{n 2}+k_{n f}\left(2+\varphi_{2}\right)} \text { where }, \frac{k_{n f}}{k_{f}}=\left(\frac{k_{n 1}+2 k_{f}-2 \varphi_{1}\left(k_{f}-k_{n 1}\right)}{k_{n 1}+2 k_{f}+\varphi_{1}\left(k_{f}-k_{n 1}\right)}\right)
\end{aligned}
$$




$$
\mathrm{c5}=\frac{1}{\left(\rho C_{p}\right)_{h n f}}=\frac{1}{\left(1-\varphi_{2}\right)\left[\left(1-\varphi_{1}\right)\left(\rho C_{p}\right)_{f}+\varphi_{1}\left(\rho C_{p}\right)_{n 1}\right]+\varphi_{2}\left(\rho C_{p}\right)_{n 2}}
$$

Local skin friction coefficient $C_{f}$, Nusselt number $\mathrm{Nu}_{\mathrm{x}}$ and Sherwood numbers $S h_{x}$ are given by

$$
\begin{aligned}
& R e_{x}^{\frac{1}{2}} C_{f}=4 c^{\frac{1}{2}} \frac{\mu_{h n f}}{\mu_{f}} f^{\prime \prime}(0), R e_{x}^{-\frac{1}{2}} N u_{x}=-2 c^{\frac{1}{2} \frac{k_{h n f}}{k_{f}}} \theta^{\prime}(c), \\
& R e_{x}^{\frac{-1}{2}} S h_{x}=-2 c^{\frac{1}{2}} \phi^{\prime}(c)=2 c^{\frac{1}{2}} \frac{N t}{N b} \theta^{\prime}(c)
\end{aligned}
$$

\section{Numerical Procedure and Result Discussion}

Numerical investigation of a mixed convective steady non-isothermal hybrid nanofluid flow moving thin needle containing different nanoparticles is studied extensively. Extensive numerical MAPLE software scheme computations that can accommodate complex boundary conditions (10) and multiple nonlinear coupled boundary layer Eq. (7)-(9) have been performed and all results are visualised in Figure 2 to Figure 16. Once the velocity, temperature, and nanoparticle concentration variables are evaluated, the skin friction, Nusselt number, and Sherwood number may be readily computed, compared with previously published results, and documented in Table 2 and Table 3. Further, the computed results of Skin friction, Nusselt number, and Sherwood number for the other parameters are presented in Table 4. To validate the present numerical results, we consider various volume fraction $\varphi_{2}$ of $\mathrm{Cu}$, while the volume fraction $\varphi_{1}=0.1$ of $\mathrm{Al}_{2} \mathrm{O}_{3}$ is kept fixed. The values of $f^{\prime \prime}(c)$ and $-\theta^{\prime}(c)$ when $\phi_{1}=\phi_{2}=0$ (regular fluid), $\varepsilon=S c=0$ and $\operatorname{Pr}=0.7$ for various values of $c$ in the absence of $N t$ and $N b$ are displayed in Table 2 and found good accuracy to run further simulations $[17,27]$. On the other hand, Table 3 is provided to describe the values of $f^{\prime \prime}(c)$ and $-\theta^{\prime}(c)$ for Cu-water nanofluid when $\varphi_{1}=\varepsilon=S c=0$ and $\operatorname{Pr}=7$ with various values of $\mathrm{c}$ and $\varphi_{2}$ in the absence of $N t$ and $\mathrm{Nb}$. The present numerical results are compared with the previous results obtained and show a favorable agreement [27]. For less the needle size, the enhancement of $f^{\prime \prime}(c)$ and $-\theta^{\prime}(c)$ can be observed from Table 2 to Table 4 and observed that $\varphi_{2}$ tend to increase the values of $f^{\prime \prime}(\mathrm{c})$ and but decrease the values of $-\theta^{\prime}$ (c) as $\varphi_{2}$ increases. MAPLE software scheme and this method was used by several researchers, for instance, to calculate their results more accurately $[28,29]$.

Table 2

Values of $f^{\prime \prime}(c)$ and $-\theta^{\prime}(c)$ for $\varphi_{1}=\varphi_{2}=0, \varepsilon=S c=0, \operatorname{Pr}=0.733$ with the value of $c$

\begin{tabular}{llllll}
\hline c & Grosan and Pop [17] & Waini et al., [27] & Present work & Grosan and Pop [17] - & Present work - \\
& $f^{\prime \prime}(c)$ & $f^{\prime \prime}(c)$ & $f^{\prime \prime}(c)$ & $\theta^{\prime}(c)$ & $\theta^{\prime}(c)$ \\
\hline 0.1 & 1.289074 & 1.288778 & 1.317999 & 2.441675 & 2.535714 \\
\hline
\end{tabular}

\section{Table 3}

Values of $f^{\prime \prime}(c)$ and $-\theta^{\prime}(c)$ for regular fluid $\left(\varphi_{1}=\varphi_{2}=0\right)$ when $(\varepsilon=S c=0)$ and $\operatorname{Pr}=$ 7 with the various values of $\mathrm{c}$ and $\varphi_{2}$, where $N b$ and $N t$ are absent

\begin{tabular}{llllll}
\hline \multicolumn{2}{l}{$f^{\prime \prime}(c)$} & & & $-\theta^{\prime}(c)$ & \\
$c$ & $\varphi_{2}$ & Waini et al., [27] & Present work & Waini et al., [27] & Present work \\
\hline 0.1 & 0.05 & 1.347125 & 1.365640 & 3.681817 & 3.688617 \\
& 0.1 & 1.381635 & 1.394255 & 3.586427 & 3.588975 \\
& 0.2 & 1.404050 & 1.413123 & 3.389682 & 3.389044 \\
\hline
\end{tabular}


Figure 2 to Figure 4 exhibit the disparity of velocity, temperature and concentration sketches through dissimilar quantities of mixed convection parameter $\xi$, where $\operatorname{Pr}=6.2, N r=0.1, P=$ $1, E c=0.1, G a=1.25, S c=0.5, \phi_{1}=0.1, a=6, R e=1, \phi_{2}=0.1, c=0.1, \varepsilon=-1$. In Figure 2, when the values of $\xi$ increase, the fluid velocity is increased, then heat is dispersed more quickly in the surrounding and as the consequence, the fluid temperature is reduced, as shown in Figure 3 . This phenomenon occurs because of the increasing mixed convection parameter has accelerated the fluid inside the boundary layer. In detail from Figure 2, the velocity reports magnify through an escalating in mixed convection quantity for both the nanoparticles considered, the elucidations of that performance reveal that the momentum boundary layer growth is accelerated the fluid motion. On the other hand, temperature reports lessen through an escalating in mixed convection quantity in the whole liquid region. Further, an improvement in the mixed convection quantity enhances concentration results rapidly, asymptotically satisfies the free stream conditions (10).

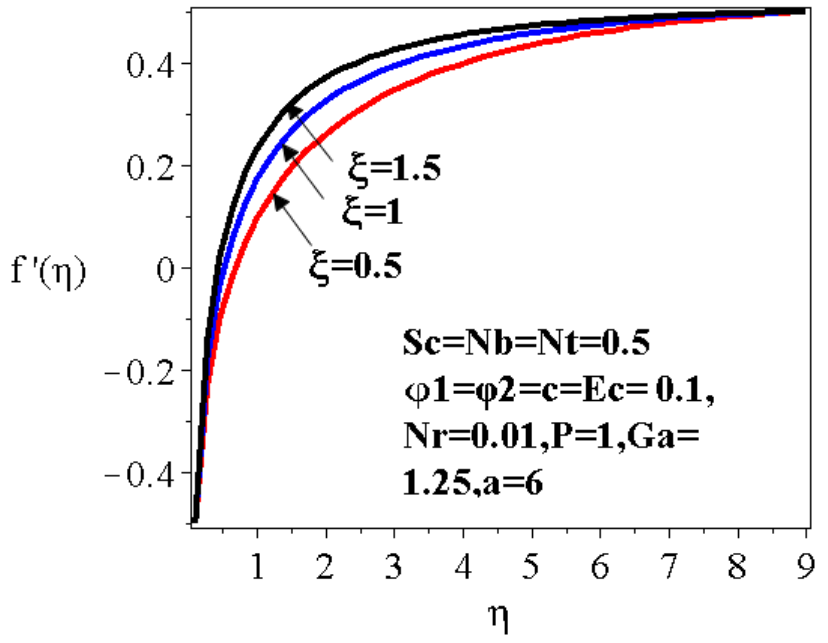

Fig. 2. Impact of $\xi$ on $f^{\prime}(\eta)$

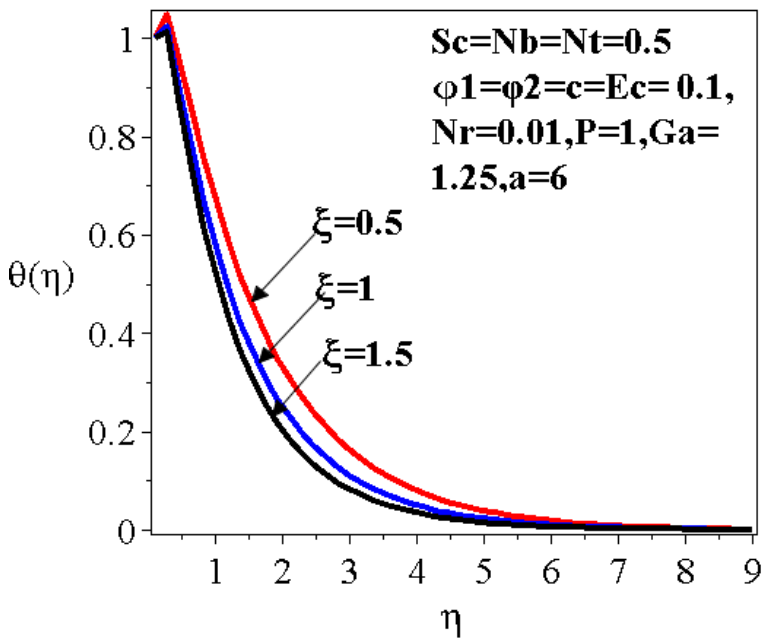

Fig. 3. Impact of $\xi$ on $\theta(\eta)$

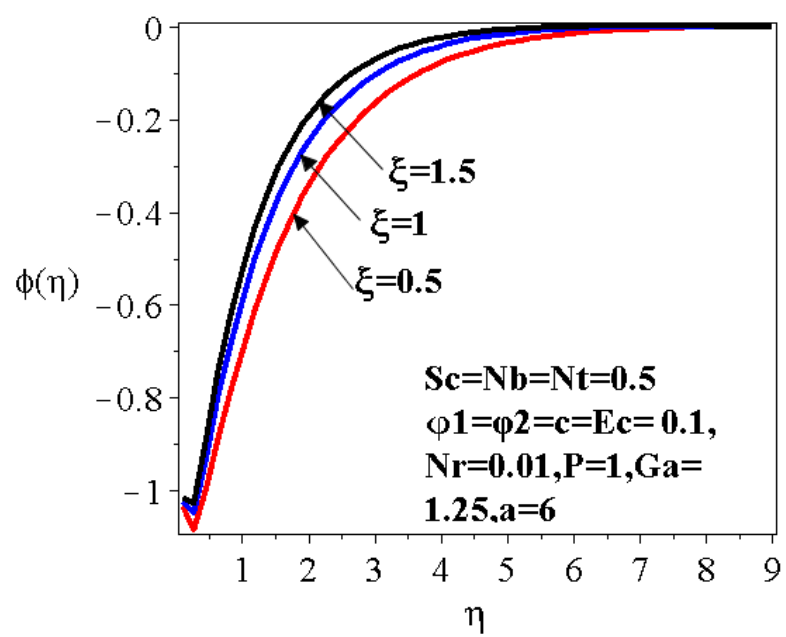

Fig. 4. Impact of $\xi$ on $\phi(\eta)$

Figure 5 to Figure 7 discloses the consequences of solute buoyancy parameter $N r$, on the liquid velocity, temperature, and concentration constituents. In Figure 5, by increasing $\mathrm{Nr}$, the buoyancy force increases which enhance the velocity field. As a result, the temperature field is decreased (see Figure 6). Higher values of solute buoyancy parameter $\mathrm{Nr}$ correspond to the decrease in temperature and thermal boundary layer thickness. The velocity improved by an increase in solutal buoyancy 
parameter $\mathrm{Nr}$, all over the liquid section. Generally, concentration buoyancy parameter appears in the momentum equation, the thermal Grashof quantity $G r$, implies qualified outcome of the heat buoyancies strength for the glutinous hydrodynamic vigor during the edge stratum, near the same time, as the mass Grashof's quantity $G m$, established the ratio for the concentration buoyancies strength to the glutinous hydrodynamic vigor. As accepted the nano liquid rapidly increases by asset of the intensification of solutal buoyancy's service. The rapidity delivery increases speedily next to the thin needle afterward, those in turn downs effortlessly for the gratuitous stream number. Hence, frontier layers width enlarges through boost up in solutal buoyancy parameter. i.e., the improvement $\mathrm{Nr}$ prepared the liquid movement upsurges for temperature. Therefore, the resulting temperature was enhanced by an augment in the concentration buoyancy parameter. Further, an improvement in the concentration buoyancy parameter reduces the concentration result rapidly.

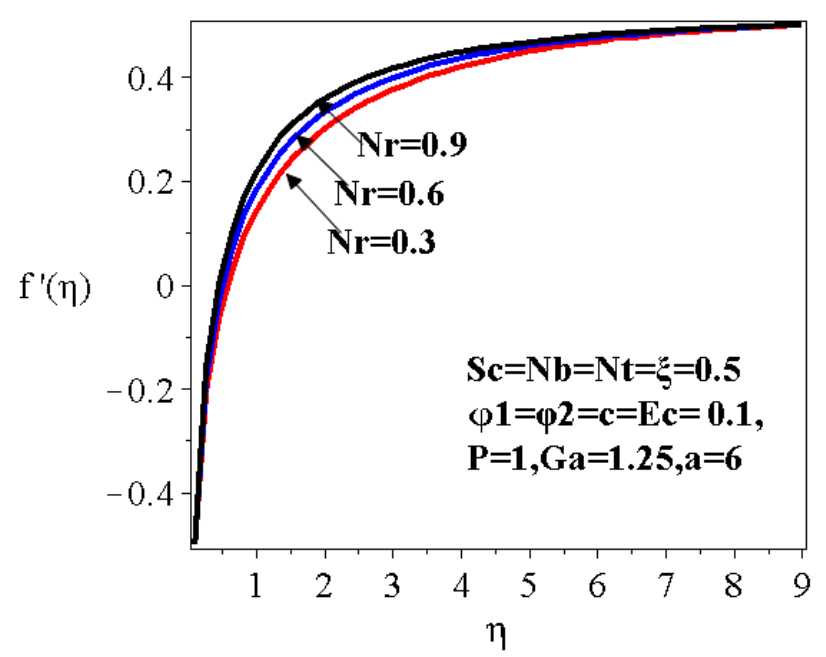

Fig. 5. Impact of $\mathrm{Nr}$ on $f^{\prime}(\eta)$

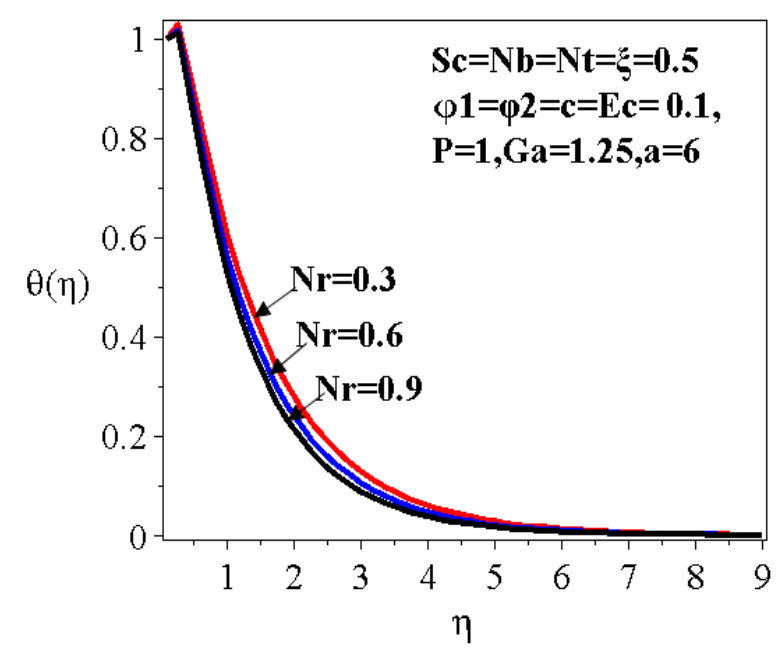

Fig. 6. Impact of $\mathrm{Nr}$ on $\theta(\eta)$

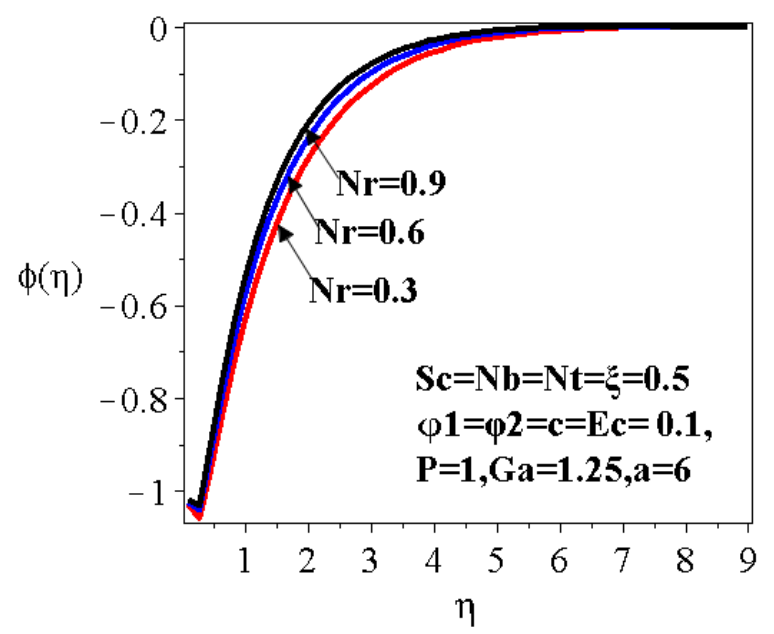

Fig. 7. Impact of $\mathrm{Nr}$ on $\phi(\eta)$

Figure 8 to Figure 10 visualize the response in radial velocity, temperature and concentration distributions with power law constant $P$. $P=0$ corresponds to uniform surface temperature, $P=$ $1 / 3$ corresponds uniform surface heat flux and $P=1$ corresponds isothermal surface. As seen, radial flow rate profiles diminish due to rising power law constant that resulted in rising nanofluid bonding strength. As power law constant appeared in boundary condition (5) depending on indexing, which diminishes the viscous force due to radial flow. However, an opposite in the heat distribution 
responses is noticed due to strong resistance to the heat generated. A more significant increment is computed throughout the concentration liquid region with a rise in power law constant.

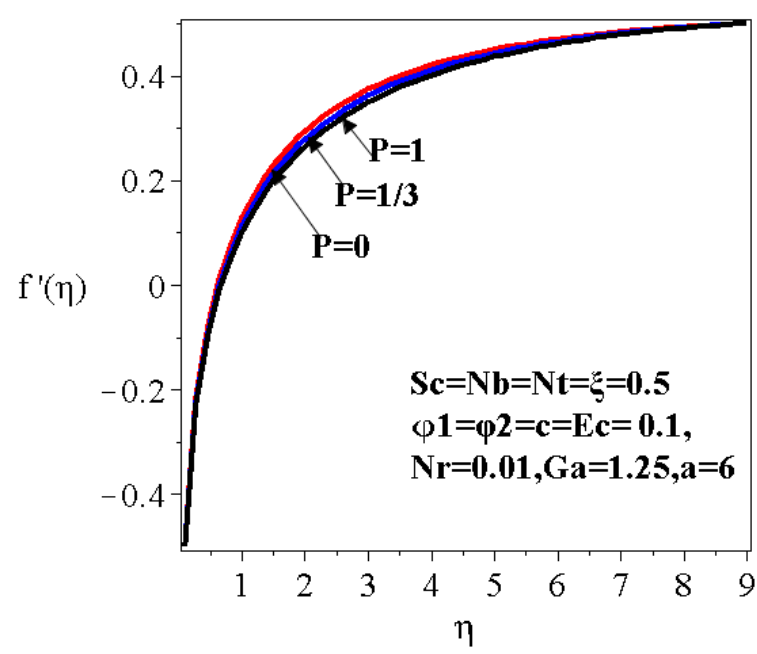

Fig. 8. Impact of P on $f^{\prime}(\eta)$

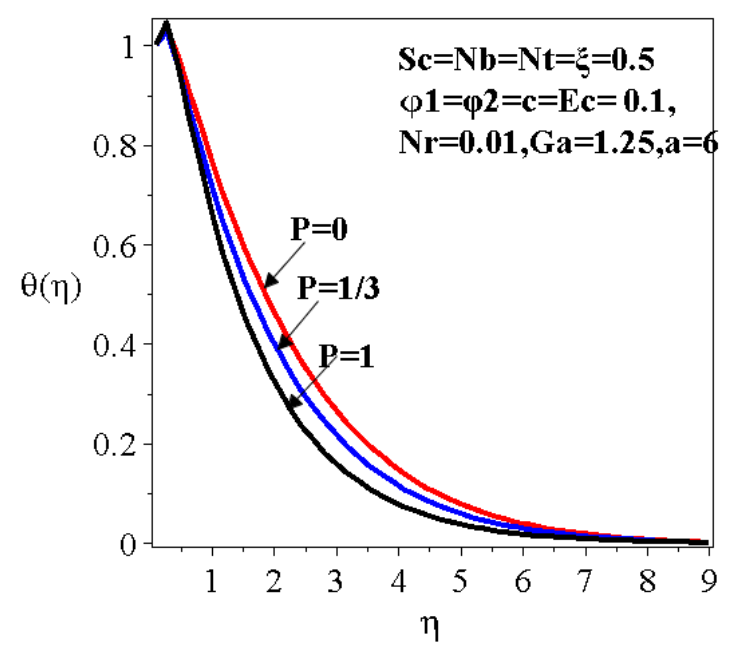

Fig. 9. Impact of $\mathrm{P}$ on $\theta(\eta)$

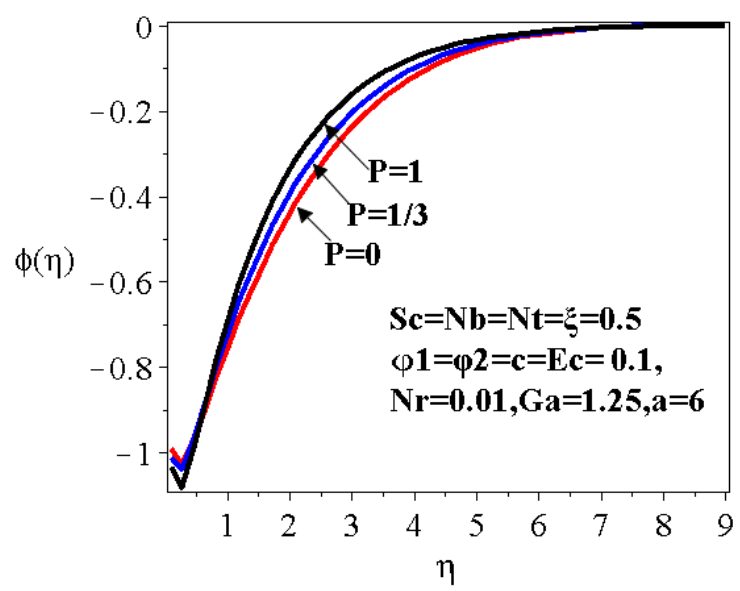

Fig. 10. Impact of $\mathrm{P}$ on $\phi(\eta)$

Figure 11 to Figure 13 illustrates the distributions in velocity, temperature, and concentration with Eckert number, Ec. Eckert number expresses the relative contribution of kinetic energy in the nanopolymer flow to the boundary layer enthalpy difference. It features in the viscous (mechanical) heating equation. Even relatively small values of $E c$ exert a significant influence on thermal field. Also, Eckert number acts an appreciated part in the description of continuum mechanics. Notable enhancement is induced in radial flow rate. From this Figure 12, it can be highlighted that an increase in the Eckert number Ec results the enhancement in temperature profile $\theta(\eta)$ and thermal boundary layer thickness. This phenomenon of temperature enhancement occurs as heat energy is stored in the fluid due to frictional heating. In precise, an increase in Eckert number is observed to strongly elevate temperatures throughout the boundary layer regime, irrespective of the nanoparticle considered. There is an increasing conversion of kinetic energy in the boundary layer flow to thermal energy owing to internal friction with higher Eckert numbers. Hence, thermal boundary layer thickness is therefore also enhanced with the dissipation effect. However, a strong depletion in nanoparticle concentration magnitudes is observed with a rise in Eckert number. Asymptotically smooth solutions are achieved in the free stream confirming the prescription of an adequately large infinity boundary condition in the MAPLE quadrature code. 


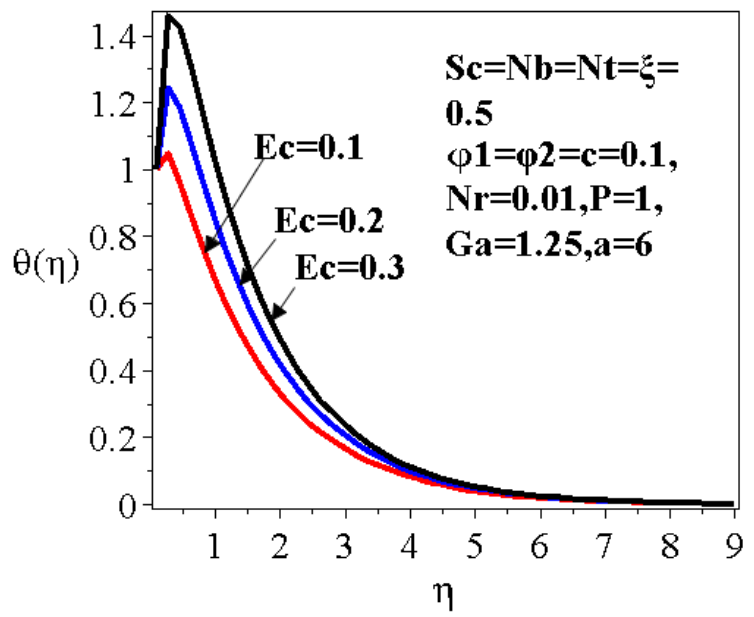

Fig. 12. Impact of Ec on $\theta(\eta)$

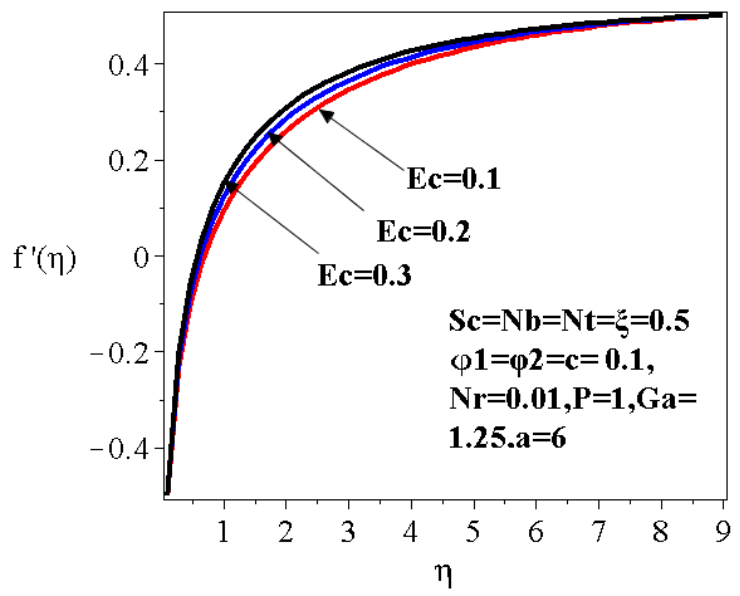

Fig. 11. Impact of Ec on $f^{\prime}(\eta)$

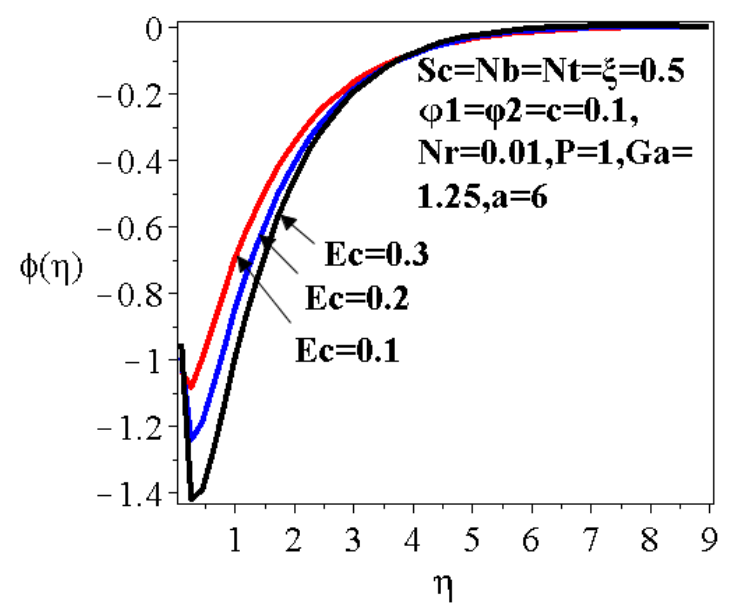

Fig. 13. Impact of Ec on $\phi(\eta)$

Figure 14 to Figure 16 shows the evolution in $f^{\prime}(\eta), \theta(\eta), \phi(\eta)$ profiles for different nanoparticles with transverse coordinate to a modification in nanoparticle volume fraction $\phi_{2}$. It is evident that a strong declination in the flow is generated with a higher fractional volume of nanoparticles i.e., the thickness of the hydrodynamic boundary layer reduces. It is apparent from Figure 15 that a strong accentuation in temperature is mobilized with higher nanoparticle volume fractions i.e., greater doping percentage of the base fluid. Therefore, thickness of thermal boundary layer increases. The flow distribution indeed confirms the non-trivial effect of nanoparticle doping as a strong mechanism for elevating both convection and conduction coefficients. Hence, nanofluids are effective for energizing base fluids without the clogging effects encountered with micro-scaled particles. They increase the thermal efficiency of the process and these are beneficial $n$ coating dynamics since the extra mechanism is available for regulating heat transfer effects and more precisely manipulating finishing characteristics. However, a strong depletion in nanoparticle concentration magnitudes is observed with a rise in volume fraction. 


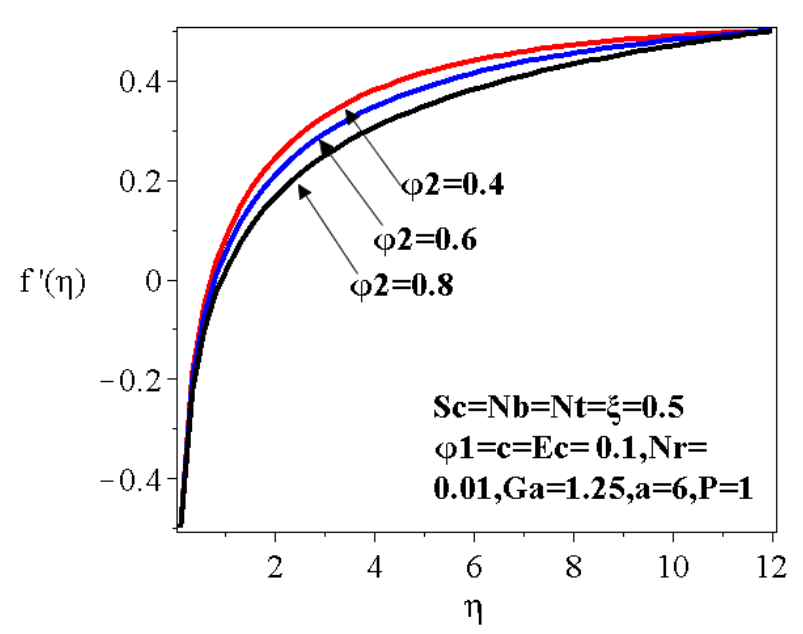

Fig. 14. Impact of $\varphi_{2}$ on $f^{\prime}(\eta)$

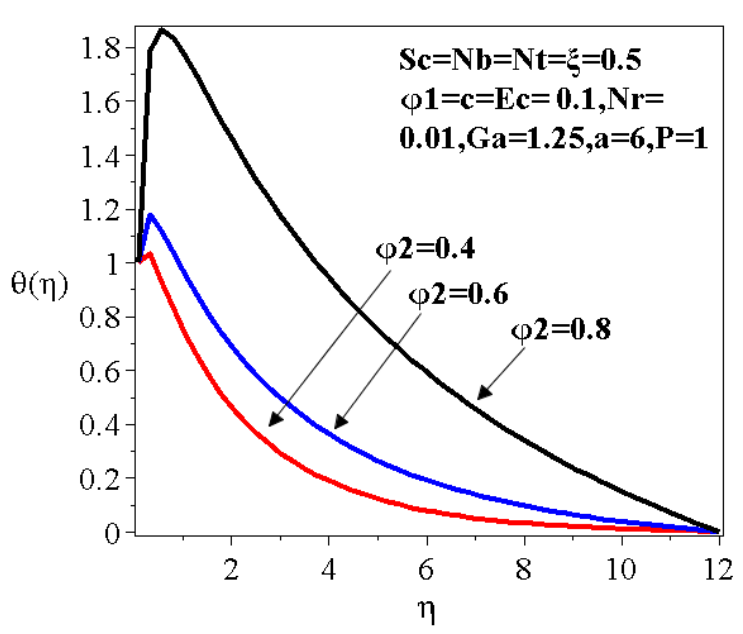

Fig. 15. Impact of $\varphi_{2}$ on $\theta(\eta)$

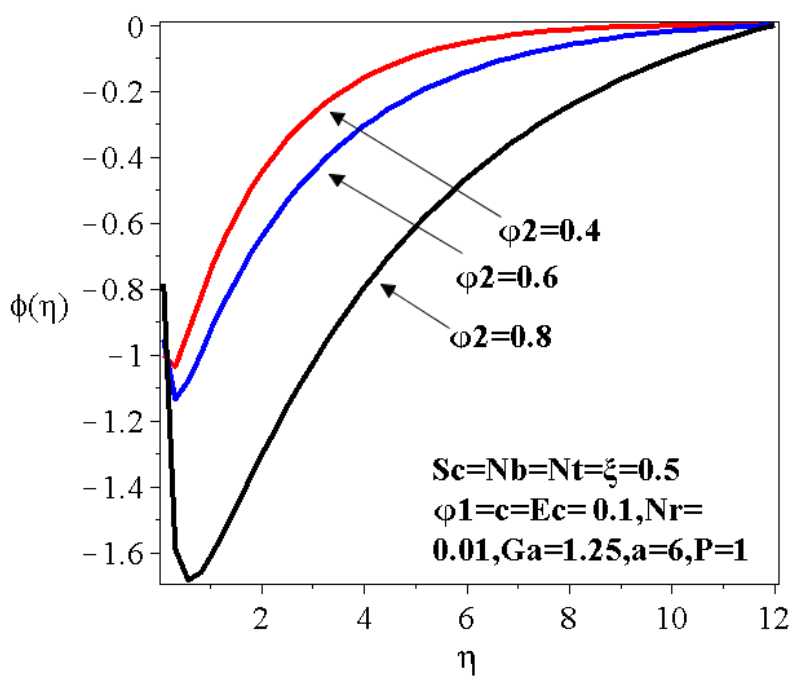

Fig. 16. Impact of $\varphi_{2}$ on $\phi(\eta)$

Table 4 show that with enhancing $\phi_{2}, \xi, P, N r$ and $E c$ trends are as follows; with increasing volume fraction $\phi_{2}$, skin friction, $f^{\prime \prime}(\eta)$ and Sherwood number, $\phi^{\prime}(\eta)$ are reduced whereas Nusselt number $\theta^{\prime}(\eta)$ is elevated. With greater mixed convection parameter $\xi$, skin friction and Nusselt number are elevated and Sherwood number is reduced. With greater power law constant $P$, skin friction and Sherwood number are reduced whereas Nusselt number is elevated. With an increase in solutal buoyancy parameter $\mathrm{Nr}$, skin friction and Nusselt number are strongly elevated but reduces the Sherwood number. Finally, Grater Ec values decrease Sherwood number but increase skin friction and Nusselt number. 


\section{Table 4}

Skin friction coefficient, Nusselt number, and Sherwood numbers and the values of another parameter

\begin{tabular}{|c|c|c|c|c|c|c|c|}
\hline$\varphi_{2}$ & $\xi$ & $P$ & $\mathrm{Nr}$ & Ec & $f^{\prime \prime}(\eta)$ & $\theta^{\prime}(\eta)$ & $\phi^{\prime}(\eta)$ \\
\hline 0.4 & 0.5 & 1 & 0.01 & 0.1 & 2.5138 & 1.6685 & -1.6685 \\
\hline 0.6 & & & & & 2.4228 & 3.1664 & -3.1664 \\
\hline 0.8 & & & & & 2.2778 & 9.8917 & -9.8917 \\
\hline \multirow[t]{3}{*}{0.1} & 0.5 & 1 & 0.01 & 0.1 & 2.5873 & 1.7697 & -1.7697 \\
\hline & 1 & & & & 3.1042 & 1.8691 & -1.8691 \\
\hline & 1.5 & & & & 3.5493 & 2.1000 & -2.1000 \\
\hline \multirow[t]{3}{*}{0.1} & 0.5 & 0 & 0.01 & 0.1 & 2.7248 & 1.2201 & -1.2201 \\
\hline & & 1 & & & 2.6391 & 1.2649 & -1.2649 \\
\hline & & $\begin{array}{l}\overline{3} \\
1\end{array}$ & & & 2.6110 & 1.7691 & -1.7691 \\
\hline \multirow[t]{3}{*}{0.1} & 0.5 & 1 & 0.3 & 0.1 & 2.8474 & 1.7204 & -1.7204 \\
\hline & & & 0.6 & & 3.1304 & 1.8035 & -1.8035 \\
\hline & & & 0.9 & & 3.3867 & 1.9206 & -1.9206 \\
\hline \multirow[t]{3}{*}{0.1} & 0.5 & 1 & 0.01 & 0.1 & 2.5344 & 1.6994 & -1.6994 \\
\hline & & & & 0.2 & 2.6866 & 4.4117 & -4.4117 \\
\hline & & & & 0.3 & 2.8353 & 7.4979 & -7.4979 \\
\hline
\end{tabular}

\section{Conclusions}

MAPLE software scheme numerical solutions have been derived for incompressible mixed convection non-isothermal hybrid nanofluid transport through moving thin needle with the impacts of solar thermal radiation and viscous dissipation. Two different waters based nanofluids have been examined, of relevance to smart functional nano-polymers. Graphical results for velocity, temperature, and nanoparticle concentration distributions have been presented for different parametric cases. Skin friction, Nusselt number and Sherwood number distributions have also been computed. Key observation of the outcomes reveals that enhancement in $\xi, \mathrm{Nr}$ accelerates the boundary layer flow (thinner momentum boundary layer) whereas elevation in Eckert number induces a deceleration (thicker momentum boundary layer). Increasing Eckert number elevates temperature strongly but suppresses the nanoparticle concentration magnitudes. Higher mixed convection parameter, solute buoyancy parameter and Eckert numbers significantly elevate skin friction, and Nusselt number but weekly reduces for Sherwood number.

\section{References}

[1] Prandtl, Ludwig. "Uber Flussigkeitsbewegung bei sehr kleiner Reibung." Verhandl. 3rd Int. Math. Kongr. Heidelberg (1904) (1905): 484-491.

[2] Sundar, L. Syam, K. V. Sharma, Manoj K. Singh, and A. C. M. Sousa. "Hybrid nanofluids preparation, thermal properties, heat transfer and friction factor-a review." Renewable and Sustainable Energy Reviews 68 (2017): 185198. https://doi.org/10.1016/j.rser.2016.09.108

[3] Sarkar, Jahar, Pradyumna Ghosh, and Arjumand Adil. "A review on hybrid nanofluids: recent research, development and applications." Renewable and Sustainable Energy Reviews $43 \quad$ (2015): $164-177$. https://doi.org/10.1016/i.rser.2014.11.023

[4] Esfe, Mohammad Hemmat, Ali Alirezaie, and Mousa Rejvani. "An applicable study on the thermal conductivity of SWCNT-MgO hybrid nanofluid and price-performance analysis for energy management." Applied Thermal Engineering 111 (2017): 1202-1210. https://doi.org/10.1016/i.applthermaleng.2016.09.091

[5] Waini, Iskandar, Anuar Ishak, and loan Pop. "Flow and heat transfer of a hybrid nanofluid past a permeable moving surface." Chinese Journal of Physics 66 (2020): 606-619. https://doi.org/10.1016/i.cjph.2020.04.024

[6] Khan, Umair, Anum Shafiq, A. Zaib, and Dumitru Baleanu. "Hybrid nanofluid on mixed convective radiative flow from an irregular variably thick moving surface with convex and concave effects." Case Studies in Thermal Engineering 21 (2020): 100660. https://doi.org/10.1016/i.csite.2020.100660 
[7] Waini, Iskandar, Anuar Ishak, and loan Pop. "Transpiration effects on hybrid nanofluid flow and heat transfer over a stretching/shrinking sheet with uniform shear flow." Alexandria Engineering Journal 59, no. 1 (2020): 91-99. https://doi.org/10.1016/j.aej.2019.12.010

[8] Waini, Iskandar, Anuar Ishak, and loan Pop. "Hybrid nanofluid flow towards a stagnation point on an exponentially stretching/shrinking vertical sheet with buoyancy effects." International Journal of Numerical Methods for Heat \& Fluid Flow 31, no. 1 (2020): 216-235. https://doi.org/10.1108/HFF-02-2020-0086

[9] Yashkun, Ubaidullah, Khairy Zaimi, Nor Ashikin Abu Bakar, Anuar Ishak, and loan Pop. "MHD hybrid nanofluid flow over a permeable stretching/shrinking sheet with thermal radiation effect." International Journal of Numerical Methods for Heat \& Fluid Flow 31, no. 3 (2020): 1014-1031. https://doi.org/10.1108/HFF-02-2020-0083

[10] Waini, Iskandar, Anuar Ishak, and loan Pop. "Unsteady flow and heat transfer past a stretching/shrinking sheet in a hybrid nanofluid." International Journal of Heat and Mass Transfer 136 (2019): 288-297. https://doi.org/10.1016/i.ijheatmasstransfer.2019.02.101

[11] Waini, Iskandar, Anuar Ishak, and Ioan Pop. "Hybrid nanofluid flow and heat transfer over a permeable biaxial stretching/shrinking sheet." International Journal of Numerical Methods for Heat \& Fluid Flow 30, no. 7 (2019): 3497-3513. https://doi.org/10.1108/HFF-07-2019-0557

[12] Waini, Iskandar, Anuar Ishak, and Ioan Pop. "Hybrid nanofluid flow towards a stagnation point on a stretching/shrinking cylinder." Scientific Reports 10, no. 1 (2020): 1-12. https://doi.org/10.1038/s41598-02066126-2

[13] Idris, Muhammad Syafiq, Irnie Azlin Zakaria, and Wan Azmi Wan Hamzah. "Heat Transfer and Pressure Drop of Water Based Hybrid Al2O3: SiO2 Nanofluids in Cooling Plate of PEMFC." Journal of Advanced Research in Numerical Heat Transfer 4, no. 1 (2021): 1-13.

[14] Zainal, S., C. Tan, C. J. Sian, and T. J. Siang. "ANSYS simulation for Ag/HEG hybrid nanofluid in turbulent circular pipe." Journal of Advanced Research in Applied Mechanics 23, no. 1 (2016): 20-35.

[15] Lee, Lawrence L. "Boundary layer over a thin needle." The Physics of Fluids 10, no. 4 (1967): 820-822. https://doi.org/10.1063/1.1762194

[16] Waini, Iskandar, Anuar Ishak, and loan Pop. "Hybrid nanofluid flow and heat transfer past a vertical thin needle with prescribed surface heat flux." International Journal of Numerical Methods for Heat \& Fluid Flow 29, no. 12 (2019): 4875-4894. https://doi.org/10.1108/HFF-04-2019-0277

[17] Grosan, T., and I. Pop. "Forced convection boundary layer flow past nonisothermal thin needles in nanofluids." Journal of Heat Transfer 133, no. 5 (2011): 054503. https://doi.org/10.1115/1.4003059

[18] Soid, Siti Khuzaimah, Anuar Ishak, and loan Pop. "Boundary layer flow past a continuously moving thin needle in a nanofluid." $\quad$ Applied $\quad$ Thermal $\quad$ Engineering $114 \quad$ (2017): https://doi.org/10.1016/j.applthermaleng.2016.11.165

[19] Momin, Gaffar G. "Experimental investigation of mixed convection with water-Al2O3 \& hybrid nanofluid in inclined tube for laminar flow." International Journal of Scientific \& Technology Research 2, no. 12 (2013): 195-202.

[20] Ahmad, Syakila, Norihan M. Arifin, Roslinda Nazar, and loan Pop. "Mixed convection boundary layer flow along vertical thin needles: Assisting and opposing flows." International Communications in Heat and Mass Transfer 35, no. 2 (2008): 157-162. https://doi.org/10.1016/j.icheatmasstransfer.2007.07.005

[21] Trimbitas, Radu, Teodor Grosan, and loan Pop. "Mixed convection boundary layer flow along vertical thin needles in nanofluids." International Journal of Numerical Methods for Heat \& Fluid Flow 24, no. 3 (2014): 579-594. https://doi.org/10.1108/HFF-05-2012-0098

[22] Khan, Umair, Aurang Zaib, Ilyas Khan, Dumitru Baleanu, and El-Sayed M. Sherif. "Comparative investigation on MHD nonlinear radiative flow through a moving thin needle comprising two hybridized AA7075 and AA7072 alloys nanomaterials through binary chemical reaction with activation energy." Journal of Materials Research and Technology 9, no. 3 (2020): 3817-3828. https://doi.org/10.1016/i.jmrt.2020.02.008

[23] Khan, Umair, A. Zaib, Ilyas Khan, and Kottakkaran Sooppy Nisar. "Dual solutions of nanomaterial flow comprising titanium alloy (Ti6Al4V) suspended in Williamson fluid through a thin moving needle with nonlinear thermal radiation: stability scrutinization." Scientific Reports 10, no. 1 (2020): 1-15. https://doi.org/10.1038/s41598-02077996-x

[24] Chamkha, A. J. "Solar Radiation Assisted Natural Convection in Uniform Porous Medium Supported by a Vertical Flat Plate." Journal of Heat Transfer 119 (1997): 89-96. https://doi.org/10.1115/1.2824104

[25] Chamkha, Ali J., Camille Issa, and Khalil Khanafer. "Natural convection from an inclined plate embedded in a variable porosity porous medium due to solar radiation." International Journal of Thermal Sciences 41, no. 1 (2002): 73-81. https://doi.org/10.1016/S1290-0729(01)01305-9

[26] Hamid, Aamir. "Terrific effects of Ohmic-viscous dissipation on Casson nanofluid flow over a vertical thin needle: buoyancy assisting \& opposing flow." Journal of Materials Research and Technology 9, no. 5 (2020): 11220-11230. https://doi.org/10.1016/i.jmrt.2020.07.070 
[27] Waini, Iskandar, Anuar Ishak, and Ioan Pop. "Hybrid nanofluid flow past a permeable moving thin needle." Mathematics 8, no. 4 (2020): 612. https://doi.org/10.3390/math8040612

[28] Khan, W. A., and A. Aziz. "Natural convection flow of a nanofluid over a vertical plate with uniform surface heat flux." International Journal of Thermal Sciences 50, no. 7 (2011): $1207-1214$. https://doi.org/10.1016/j.ijthermalsci.2011.02.015

[29] Makinde, Oluwole D., and A. Aziz. "Boundary layer flow of a nanofluid past a stretching sheet with a convective boundary condition." International Journal of Thermal Sciences 50, no. 7 (2011): 1326-1332. https://doi.org/10.1016/i.ijthermalsci.2011.02.019 